Cite this: Phys. Chem. Chem. Phys., 2014, 16, 12510

Received 11th April 2014, Accepted 29th April 2014

DOI: $10.1039 / c 4 c p 01582 g$

www.rsc.org/pccp

\title{
Conversion efficiency of skutterudite-based thermoelectric modules
}

\author{
James R. Salvador, ${ }^{* a}$ Jung Y. Cho, ${ }^{b}$ Zuxin Ye, ${ }^{b}$ Joshua E. Moczygemba, ${ }^{c}$ \\ Alan J. Thompson, ${ }^{c}$ Jeffrey W. Sharp, ${ }^{c}$ Jan D. Koenig, ${ }^{d}$ Ryan Maloney, \\ Travis Thompson, ${ }^{e}$ Jeffrey Sakamoto, ${ }^{e}$ Hsin Wang $^{f}$ and Andrew A. Wereszczak ${ }^{f}$
}

\begin{abstract}
Presently, the only commercially available power generating thermoelectric (TE) modules are based on bismuth telluride $\left(\mathrm{Bi}_{2} \mathrm{Te}_{3}\right)$ alloys and are limited to a hot side temperature of $250{ }^{\circ} \mathrm{C}$ due to the melting point of the solder interconnects and/or generally poor power generation performance above this point. For the purposes of demonstrating a TE generator or TEG with higher temperature capability, we selected skutterudite based materials to carry forward with module fabrication because these materials have adequate TE performance and are mechanically robust. We have previously reported the electrical power output for a 32 couple skutterudite TE module, a module that is type identical to ones used in a high temperature capable TEG prototype. The purpose of this previous work was to establish the expected power output of the modules as a function of varying hot and cold side temperatures. Recent upgrades to the TE module measurement system built at the Fraunhofer Institute for Physical Measurement Techniques allow for the assessment of not only the power output, as previously described, but also the thermal to electrical energy conversion efficiency. Here we report the power output and conversion efficiency of a 32 couple, high temperature skutterudite module at varying applied loading pressures and with different interface materials between the module and the heat source and sink of the test system. We demonstrate a $7 \%$ conversion efficiency at the module level when a temperature difference of $460{ }^{\circ} \mathrm{C}$ is established. Extrapolated values indicate that $7.5 \%$ is achievable when proper thermal interfaces and loading pressures are used.
\end{abstract}

\section{Introduction}

Recent advances in thermoelectric (TE) materials research have resulted in lab-scale demonstrations of thermoelectric figures of merit (ZT) close to, or in excess of, 2.0 at temperatures of interest to automotive waste heat recovery applications (ca. $400 \mathrm{~K}$ to $900 \mathrm{~K}) \cdot{ }^{1-4}$ These advances have made the concept of passenger vehicle TE-based exhaust gas waste heat recovery considerably more attractive from a cost/benefit standpoint. ${ }^{5}$ The figure of merit, ZT, limits how efficiently a TE material can interconvert thermal and electrical energy and is defined as

\footnotetext{
${ }^{a}$ Chemical \& Materials Systems Lab, GM Global Research \& Development, MC 480-106-224, 30500 Mound Road, Warren, MI 48090, USA.

E-mail: james.salvador@gm; Fax: +1-586-986-3091; Tel: +1-586-986-5383, $+1-517-862-1376$

${ }^{b}$ Optimal Inc., 14492 North Sheldon Road \#300, Plymouth, MI 48170, USA

${ }^{c}$ Marlow Industries, Inc., 10451 Vista Park Road, Dallas, TX 75238, USA

${ }^{d}$ Fraunhofer-Institute for Physical Measurement Techniques, Heidenhofstr. 8, 79110 Freiburg, Germany

${ }^{e}$ Department of Chemical Engineering and Materials Science, Michigan State University, East Lansing, MI 48824, USA

${ }^{f}$ Materials Sciences and Technology Division, Oak Ridge National Laboratory, Oak Ridge, TN 37831, USA
}

$\mathrm{ZT}=\left(S^{2} / \rho \cdot \kappa\right) T$, where $S$ is the Seebeck coefficient, $\rho$ is the electrical resistivity, $\kappa$ is the thermal conductivity, and $T$ is the absolute temperature. The ideal efficiency of thermal to electrical energy conversion for a thermoelectric material is expressed as ${ }^{6}$

$$
\eta=\left(\frac{T_{\mathrm{H}}-T_{\mathrm{C}}}{T_{\mathrm{H}}}\right) \cdot \frac{\sqrt{1+\mathrm{ZT}_{\mathrm{avg}}}-1}{\sqrt{1+\mathrm{ZT}_{\mathrm{avg}}}+\left(T_{\mathrm{C}} / T_{\mathrm{H}}\right)}
$$

where the first parenthetical term on the right hand side of the expression is the Carnot efficiency and the second term, involving $\mathrm{ZT}_{\mathrm{avg}}$, determines what fraction of the Carnot efficiency one can obtain with a given temperature difference. The temperature at the hot side, $T_{\mathrm{H}}$, and cold side, $T_{\mathrm{C}}$, of the TE materials define this temperature difference $\left(T_{\mathrm{H}}-T_{\mathrm{C}}\right)$, and $T_{\text {avg }}$ is the average of these temperatures. We therefore aim to have the largest average ZT in the temperature range of interest. Based on the derivation of eqn (1), we can think of TE devices as heat pumps or thermal engines with electrons playing the role of the working fluid. Following this analogy, a large thermal differential in the temperature regime where the TE material has its peak ZT would result in higher conversion efficiencies. 


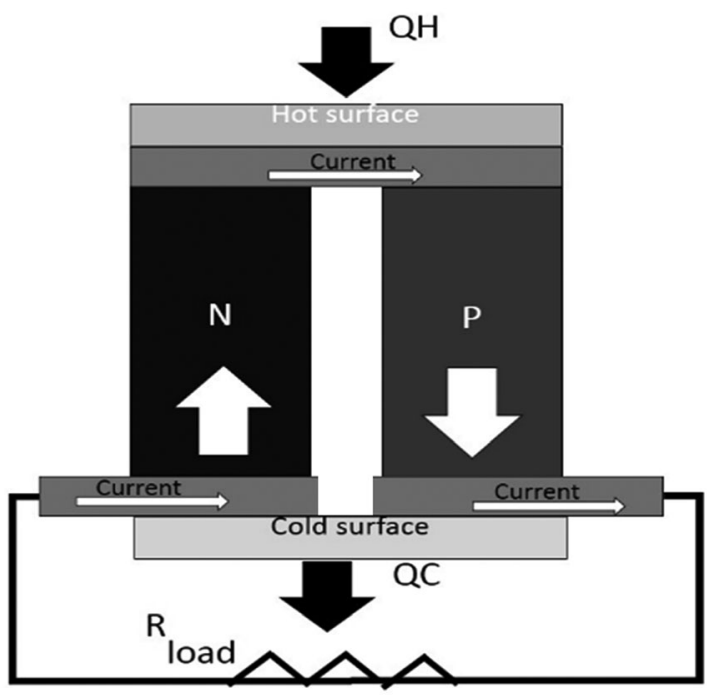

Fig. 1 Illustration of a TE unicouple with a temperature differential applied. This shows how the voltage generated under these conditions can be used to drive an external load. This is the operational condition envisioned for waste heat recovery applications. A plurality of such unicouples would be connected electrically in series to form a TE module.

An illustration of a TE unicouple composed of an arbitrary n-type and p-type semiconducting material connected electrically in series and thermally in parallel is shown in Fig. $1 .^{6}$ This figure shows how the unicouple can be used to generate electricity when a temperature difference is applied. Such a couple can also be used as a heat pump to generate a temperature differential when provided with DC electrical power input, though this is not specifically illustrated in Fig. 1.

In the past 20 years there have been numerous reports on the TE properties of a wide variety of materials systems including: $\mathrm{TtX}(\mathrm{Tt}=\mathrm{Ge}, \mathrm{Sn}$ and/or $\mathrm{Pb}$ and $\mathrm{X}=\mathrm{S}$, Se and/or $\mathrm{Te})$ and its solid solutions, skutterudites, antifluorites such as $\mathrm{Mg}_{2} \mathrm{Tt}$ $(\mathrm{Tt}=\mathrm{Si}, \mathrm{Ge}$, and/or Sn), half-Heuslers, and complex layered oxides such as $\mathrm{CaCoO}_{3} .{ }^{6}$ Reports on the power generation or thermal to electrical conversion efficiency of unicouples made from the above mentioned materials classes are quite limited and indicate the level of technical challenge associated in fabricating working devices capable of efficiently converting thermal to electrical energy. ${ }^{7-22}$

Further complicating the development efforts for high temperature TEMs is the fact that many factors extrinsic to the constituent TE materials can influence the performance of the device including: thermal and electrical resistances at interfaces, radiative thermal losses from the TE legs and other device components, and spreading thermal resistances in the module's electrically insulating ceramic layers. ${ }^{23,24}$ Many of these factors are difficult to minimize and characterize, and can be strongly influenced by the module's specification such as the selected leg height and TE material packing factor (ratio of the area of the TE materials to the area of the electrically insulating substrate).$^{25}$ Finally modules are designed to work within a system, prompting a trade-off between maximum conversion efficiency and maximum power density (power per unit area of heat exchanger surface or power per unit mass of TE materials), which is driven by characteristics of the hot and cold side heat exchangers, TE element geometry, and module packing factor. For most power generating applications maximum power density is sought, and this is particularly true for automotive applications where packaging constraints and mass are primary design drivers. ${ }^{25}$

Finally, as the focus in high-temperature thermoelectric technology begins to transition from materials discovery and optimization to module fabrication and characterization, module level metrology method development will gain significant importance. We have recently published a review article on module level measurement methods. ${ }^{26}$ There we reported on several different test systems including the system used to evaluate the modules in this report. The shortcomings of each of these systems were evaluated, and based on these findings, we proposed the design of a module test system that minimizes thermal losses in the test stand and thereby increases the accuracy of the thermal to electrical energy conversion measurement.

Here we report the thermal to electrical energy conversion efficiency of a prototypical skutterudite module. The modules are high temperature capable, with the ability to withstand hot side temperatures in excess of $525{ }^{\circ} \mathrm{C}$. The module is identical to those used in the TE generator recently tested on a production Chevrolet Suburban. The power output of this TEG was far below thermal modelling predictions and called into question how well the TEMs performed. Here we show that under higher pressure loading with proper selection of thermal interface materials a 32 couple prototype skutterudite module can supply $11.5 \mathrm{~W}$ of electricity with a temperature difference across the module of $460{ }^{\circ} \mathrm{C}$. This power output corresponded to an extrapolated value of $7.5 \%$ conversion efficiency at the module level, one of the highest reported values to date. The test results indicate that factors other than module function are the cause of the lower than anticipated generator performance.

\section{Experimental}

\section{Thermoelectric materials preparation}

The preparation of the skutterudite materials used in the module as well as the evaluation of their mechanical and transport properties have been reported in detail previously. ${ }^{22,27}$ To summarize, $3.0 \mathrm{~kg}$ of n-type skutterudite with the nominal composition $\mathrm{Yb}_{0.09} \mathrm{Ba}_{0.05} \mathrm{La}_{0.05} \mathrm{CO}_{4} \mathrm{Sb}_{12}$ and $3.0 \mathrm{~kg}$ of p-type skutterudite with the nominal composition $\mathrm{Mm}_{0.30} \mathrm{Fe}_{1.46} \mathrm{Co}_{2.54} \mathrm{Sb}_{12.05}$ (Mm stands for Misch metal which is alloy of $\mathrm{La}, \mathrm{Ce}, \mathrm{Pr}$ and $\mathrm{Nd}$ ) were prepared by induction melting of the elements followed by long term annealing at $650{ }^{\circ} \mathrm{C}$. Powder attrition methods were employed to reduce the annealed ingots to fine powder, followed by consolidation via spark plasma sintering. The resulting $80 \mathrm{~g}$ pucks were nearly fully dense and phase pure with the exception of two n-type pucks whose density was only $90 \%$ of the theoretical value. All materials were processed from elements to phase pure skutterudite billets at GM R\&D. Fig. 2 shows an $800 \mathrm{~g}$ lot of p-type materials. 


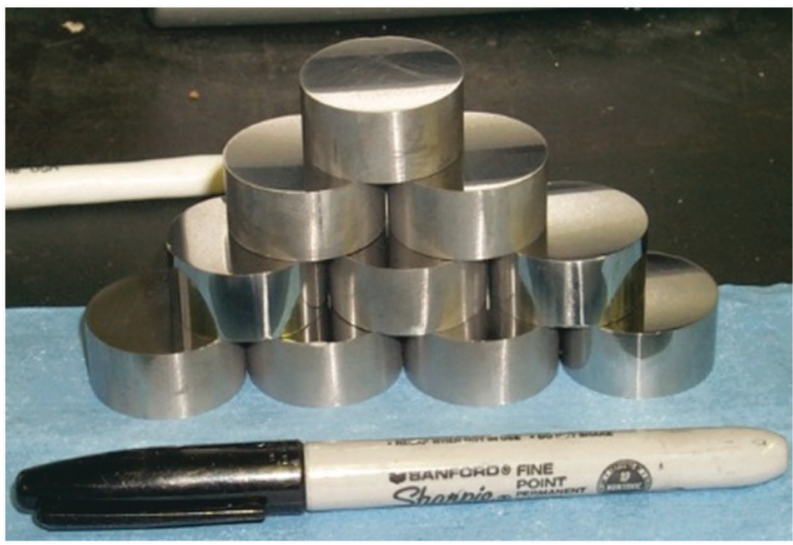

Fig. 2 Ten $80 \mathrm{~g}$ ingots of $\mathrm{p}$-type skutterudite as sintered by GM R\&D. These pucks are diced into wafers and processed into TE elements.

\section{Module fabrication}

The consolidated skutterudite pucks were shipped to Marlow Industries which diced them into $\sim 4.0 \mathrm{~mm}$ thick wafers. Molybdenum diffusion barriers were applied via an arc spraying method, and then the wafers were diced into square cross sectional legs that measured $4 \mathrm{~mm}$ on a side. The Mo diffusion barrier prevents the $\mathrm{Sb}$ in the skutterudite from reacting with the braze and metal interconnects in the module. To form TEMs, the TE elements were brazed to aluminium pads which were directly bonded to an alumina ceramic. The alumina electrically isolates the current carried in the legs and the direct bonded aluminium interconnects. The direct bonded aluminium (DBA) pads provide electrical interconnects for the TE legs, allowing for a series connection of all the components in the module. DBA pads were applied to both sides of the alumina to mitigate deformation of the ceramic during thermal processing due to differences in the coefficients of thermal expansion between these components. The double sided DBA plates, braze and TE legs were assembled in a fixture and then put through a belt oven under an inert atmosphere to melt the

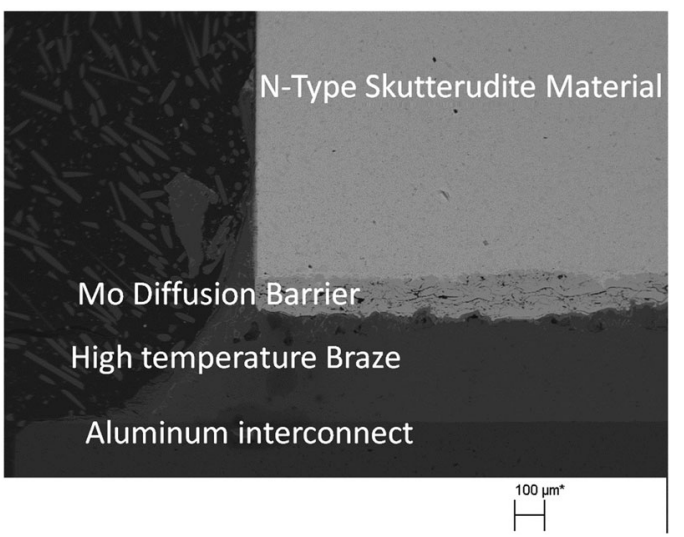

Fig. 3 Scanning electron micrograph of a sectioned TE element showing the TE material, the Mo diffusion barrier, the braze, and the aluminum interconnect. The porosity observed in the Mo diffusion barrier is likely one cause of the higher than expected module resistance.

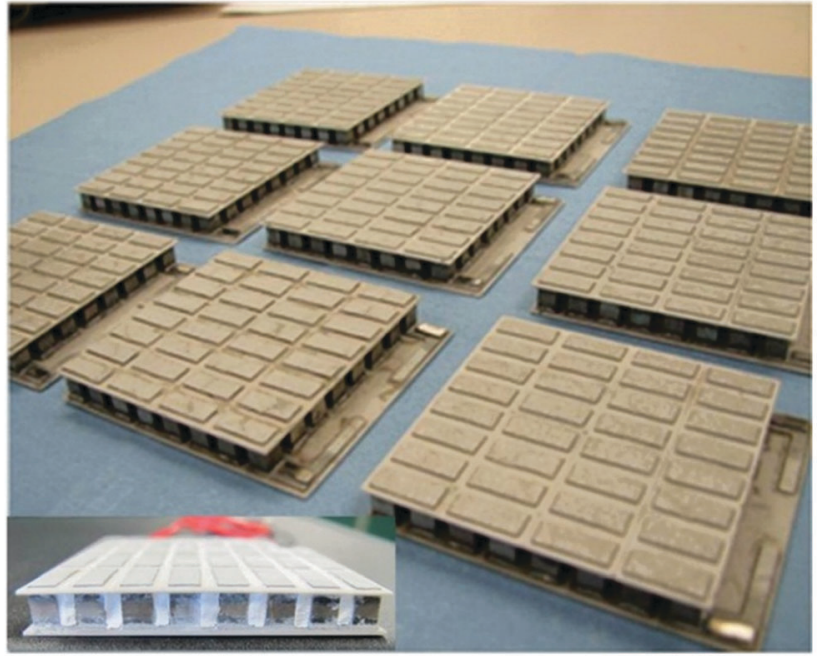

Fig. 4 A photograph of the first lot of nine skutterudite modules received from Marlow Industries. The inset photo in the lower left hand corner is the same type of module after aerogel encapsulation. Reproduced from ref. 22.

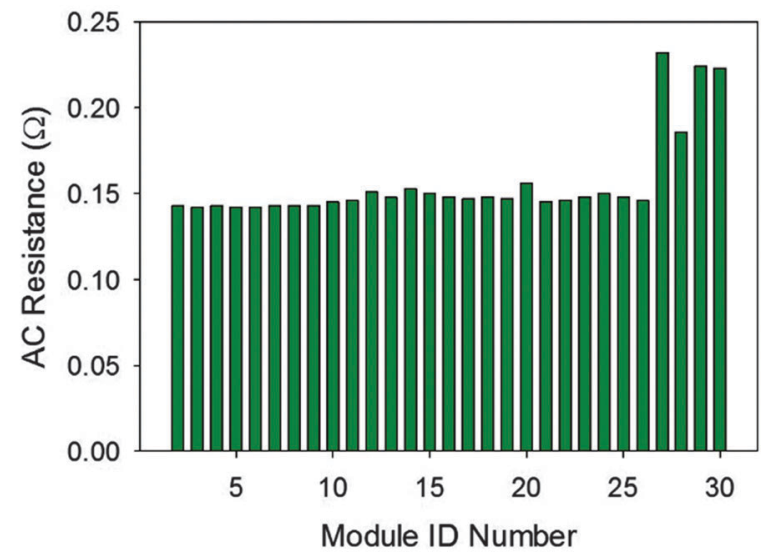

Fig. 5 The AC resistance of the thirty skutterudite modules. As can be seen there is very little variability in the resistance for the first 26 modules. The last four modules were made with materials with higher levels of porosity, and as a result these modules had significantly higher resistances. 24 modules were required for the generator build and so the higher resistance modules were not used.

braze. After brazing, the hot side ceramic was sectioned to provide passive thermal strain relief in the module while in operation.

Fig. 3 shows an electron micrograph of a sectioned TE element and its joining layers to form the module. As can be seen there is some degree of porosity in the Mo diffusion barrier layer. Thirty modules, each containing $32 \mathrm{p}-\mathrm{n}$ couples, were prepared. Each module was approximately $5 \mathrm{~cm}$ by $5 \mathrm{~cm}$ in area on the hot side. Fig. 4 shows a picture of nine of the TEMs as well as a close-up view of one in the inset. Based on the TE element cross section and the dimensions of the ceramics, the TEMs had a packing factor of $40 \%$. Fig. 5 shows the room temperature AC resistance of each module. As can be seen, with the exceptions of modules 27-30 which were made from the 
n-type materials with a higher level of porosity, there is little variability in their resistance.

\section{Module encapsulation}

All modules were sent to Michigan State University for aerogel encapsulation. The aerogel provides protection against sublimation of $\mathrm{Sb}$ under high temperature operation and is also highly thermally insulating which reduces convective and radiative thermal loss through the dead space in the TEM. The aerogel employed is a high temperature stable silica based material that can be dried ambiently. The ability to ambiently dry these gels is a major processing advantage in comparison to typical aerogel materials which generally require supercritical fluid drying techniques to maintain the microstructures. Such processing conditions require high pressure, special equipment, and long processing times. Briefly, methyltrimethoxysilane (Alfa Aesar) was combined with de-ionized water, sodium hydroxide (Alfa Aesar) and methanol (Alfa Aesar) to form a clear solution. $^{28}$ Titania powder (opacification) and quartz fibers (St Gobain) were also added during the mixing process as described by Maloney et $a l^{28}$ The solution (aka sol) was cast between the skutterudite elements in the module, sealed in custom fabricated poly ethylene molds, allowed to gel (after 1 hour), and aged for three days. After three days, the seal was broken and the gel/thermoelectric module assemblies were dried under ambient conditions (1 atmosphere pressure at $25{ }^{\circ} \mathrm{C}$ ). The lower left hand inset of Fig. 4 shows a picture of a skutterudite module with aerogel cast into the spaces between the elements.

\section{Module measurements}

The thermoelectric module test system at the Fraunhofer Institute for Physical Measurement Techniques measures the electrical output power $\left(P_{\text {out }}\right)$, short circuit current $\left(I_{\mathrm{SC}}\right)$, open circuit voltage $\left(V_{\text {OC }}\right)$ and efficiency $(\eta)$ of standard construction TEMs. It can accommodate dimensions between $10 \mathrm{~mm} \times$ $10 \mathrm{~mm}$ and $80 \mathrm{~mm} \times 80 \mathrm{~mm}$ and a temperature range from $15{ }^{\circ} \mathrm{C}$ up to $700{ }^{\circ} \mathrm{C}$. Fig. 6 shows the Fraunhofer TEM measurement setup, which consists of a water-cooled vacuum chamber that houses the hot and cold side heat exchangers, between which the TEM is placed. The hot side heat exchanger has a home-built heater capable of sustaining $600{ }^{\circ} \mathrm{C}$ for long periods and short excursions to $700{ }^{\circ} \mathrm{C}$ (for temperature cycling tests). The heater is pressed onto the TEM and the cold side heat exchanger by a three point contact with mechanically adjustable load settings. The cold side heat exchanger is connected to a closed cycle oil thermostat with a temperature controller. The temperature of the cold side can be varied from $15{ }^{\circ} \mathrm{C}$ up to $\sim 100{ }^{\circ} \mathrm{C}$, and its temperature is measured at different places directly under the TEM inside the cold side heat exchanger using 4-wire Pt100 temperature sensors. Below the cold side heat exchanger, three pressure sensors are placed to measure, in situ, the force distribution in order to assess the pressure loading. The three loading points help facilitate uniform thermal contact. A radiation shield and thermal insulation are used to reduce thermal losses from parasitic heat flow and radiation.
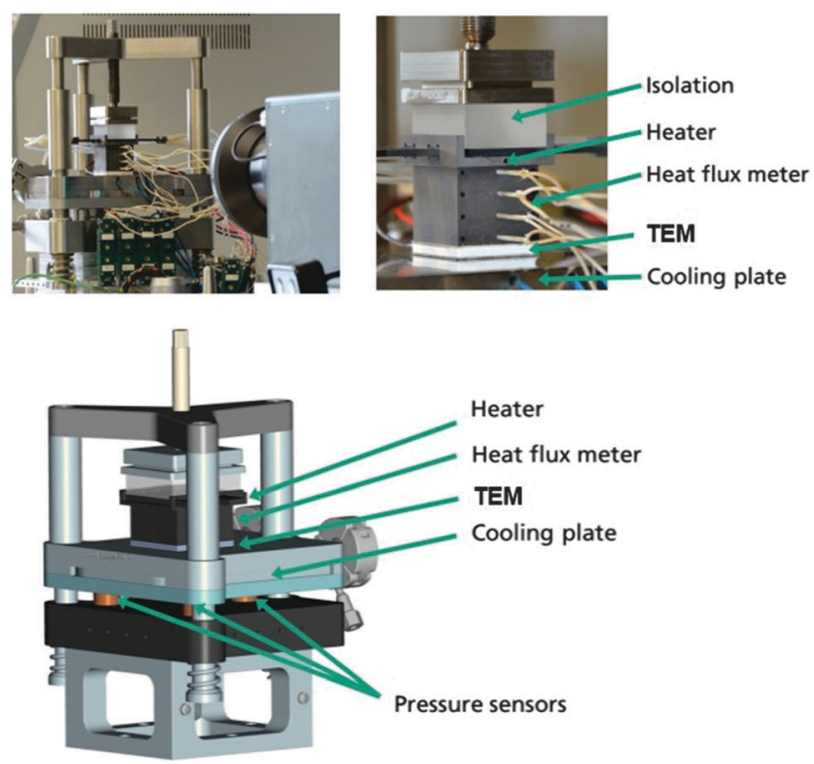

Fig. 6 The top two images are pictures of the high temperature module test system at the Fraunhofer-Institute for Physical Measurement Techniques. Top left is a full system view showing the module clamping system, the thermal isolation block heater, 1-D heat flow meter, and the cold side heat rejection plate. The top right image is a close-up view of the test stand and module with the heater, heat flux meter, module, and cold plate labeled. The bottom image is a solid model showing the main components of the test stand with all wires and thermocouples removed for clearer viewing

The measurements are performed inside a water cooled vacuum chamber that can also be filled with inert gases. The $P_{\text {out }}, I_{\mathrm{SC}}$, and $V_{\mathrm{OC}}$ are measured using a variable electrical load.

For the efficiency measurements, a home-built heat flow meter with a known thermal conductivity is placed between the heater and the TEM. The temperatures along the meter are measured with several thermocouples, and the heat flow is simulated using a 1-D heat model. The TEM efficiency is calculated using the measured heater power, the measured heat flow through the 1-D heat meter, and the maximum electrical output power. The reported efficiencies are underestimated due to the fact that the heat flow is overestimated. This is a result of radiative losses from the 1-D heat bar not being taken into account, leading to less heat being delivered to the TEM than predicted by the model. Secondly, due to limits in the load device, the maximum power output is extrapolated based on the $V_{\text {OC }}$ value and the measured resistance $\left(R_{\mathrm{int}}\right)$ of the module. The maximum power output is assumed to be when the load resistance is equal to $R_{\text {int }}$ and the TEM voltage is $1 / 2$ the $V_{\text {OC }}$ value. The efficiencies reported here are calculated by dividing the maximum power output by the heat flow in the module. However, due to Peltier and Joule effects in the module, maximum power and maximum efficiency have different operating points. The inability to trace out the full $P_{\text {out }} v s$. $I$ and $\eta v s$. $I$ curves requires these values to be extrapolated. Therefore, since the maximum power is used to calculate $\eta$, its value is underestimated. The combined error of these two effects is likely less than $1 \%$ absolute in the reported efficiency value. 
The effects of pressing force on module performance were investigated to establish to what degree the interface contact resistance between the module and the test stand could be influenced by increased pressure loading. Additionally both grafoil and aluminium foil were investigated as potential interface materials as another means to affect thermal contact resistance. In the discussion that follows, unless otherwise stated, $360 \mu \mathrm{m}$ thick pre-compressed grafoil pads were used as the thermal interface material between the module and the hot and cold junctions of the test stand.

\section{Results and discussion}

\section{Materials characterization and power output measurements}

The thermoelectric properties, microstructure and composition of the constituent skutterudite materials used for module production have been presented before and will only be summarized here. ${ }^{22,27}$ Fig. 7 shows the $\mathrm{ZT}$ as a function of temperature between $300 \mathrm{~K}$ and $750 \mathrm{~K}$ for $\mathrm{Yb}_{0.09} \mathrm{Ba}_{0.05} \mathrm{La}_{0.05} \mathrm{Co}_{4} \mathrm{Sb}_{12}$ and $\mathrm{Mm}_{0.30} \mathrm{Co}_{2.54} \mathrm{Fe}_{1.46} \mathrm{Sb}_{12}$. As can be seen the $\mathrm{ZT}$ values for the n-type material range between 1.0 and 1.2 at $500{ }^{\circ} \mathrm{C}$, values that are lower than previously reported for a comparable composition. $^{2}$ This can be traced to the higher values of $\kappa$ in the
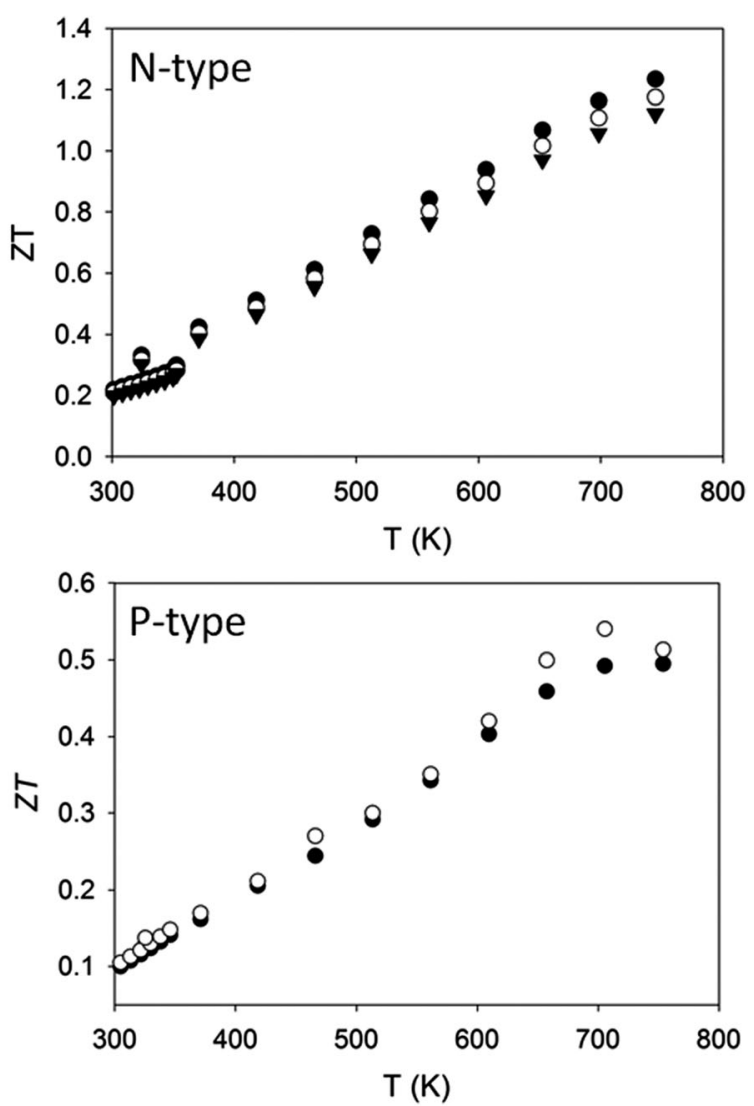

Fig. 7 Measured ZT values as a function of temperature for three of the six $500 \mathrm{~g}$ lots of $\mathrm{n}$-type skutterudite materials (top panel) and two of the three $1000 \mathrm{~g}$ lots of the $\mathrm{p}$-type skutterudite materials (bottom panel) used to construct the TE modules. Reproduced from ref. 22. materials prepared here as compared to literature values. The ZT values of the p-type materials are particularly poor with values of 0.6 at $500{ }^{\circ} \mathrm{C}$. This is far lower than the value reported by X. F. Tang et $a .^{29}$ and can be attributed to much higher $\rho$ and a $\sim 20 \%$ higher $\kappa$. The magnitude and temperature dependence of the $\mathrm{ZT}$ values for the materials used here and those reported in ref. 12 are remarkably similar. This is fortuitous and allows for a direct comparison between the upper limit values of conversion efficiency described by ref. 12 and those obtained here.

Power output and efficiency measurements were performed under two uniaxial pressures. The first, at $0.5 \mathrm{MPa}$, led to very high levels of interface thermal contact resistance on the order of $6.0 \times 10^{-4} \mathrm{~m}^{2} \mathrm{~K} \mathrm{~W}^{-1}$. This, in conjunction with the quite low $\kappa$ of the alumina at $500{ }^{\circ} \mathrm{C}\left(\sim 10 \mathrm{~W} \mathrm{~m}^{-1} \mathrm{~K}^{-1}\right)$, led to a much lower power output as compared to calculated values. This discrepancy is attributed to the temperature drops these thermal resistances impose. ${ }^{22}$ These temperature drops led to a much smaller $\Delta T$ across the TE elements $\left(\Delta T_{\mathrm{M}}\right)$ than anticipated and, as a result, a much lower $V_{\mathrm{OC}}$. The discrepancy between the predicted and measured values of $V_{\mathrm{OC}}$ as a function of the measured hot side temperature of the module is shown in Fig. 8.

We have derived this large thermal interface contact resistance value $\left(6.0 \times 10^{-4} \mathrm{~m}^{2} \mathrm{~K} \mathrm{~W}^{-1}\right)$ by using a simple 1-D thermal resistance model that treats the thermal interface contact resistance between the module surfaces and those of the heater and cooler in the test stand, the thermal resistance of the ceramics, and the integral average value of the thermal resistance of the TE materials as a series of thermal resistors to back out the approximate heat flow through the entire module under open circuit (no Peltier or Joule heating effects) conditions. The thermal resistances of the $\mathrm{n}$ - and p-type materials are treated as thermal resistances in parallel, and, for the purposes

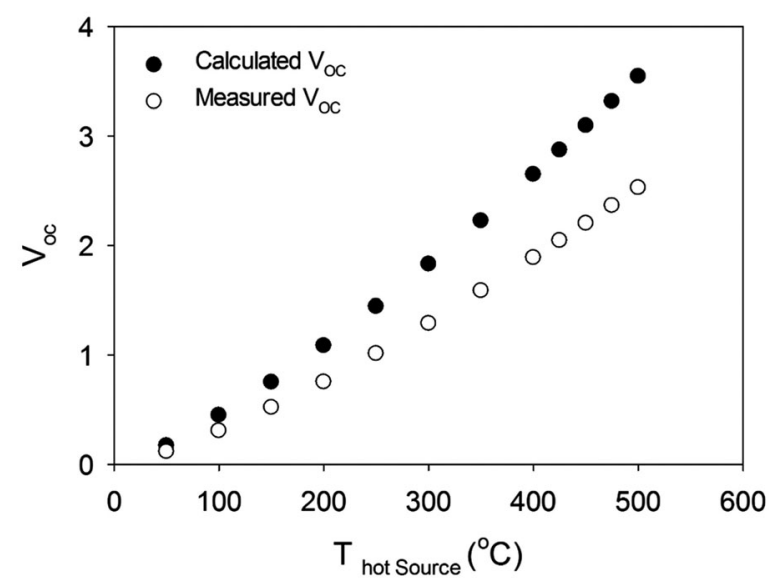

Fig. 8 A plot of the calculated $V_{O C}$ as derived from eqn (2) assuming the temperature at the hot and cold side of the element is equal to the temperature at the hot and cold side of the module (filled circles). The open circles are the measured $V_{O C}$ values. The large decrease in the measured $V_{O C}$ as compared to the calculated value is ascribed to thermal interface contact resistance between the heat source and sink and the hot and cold side of the module, respectively. 


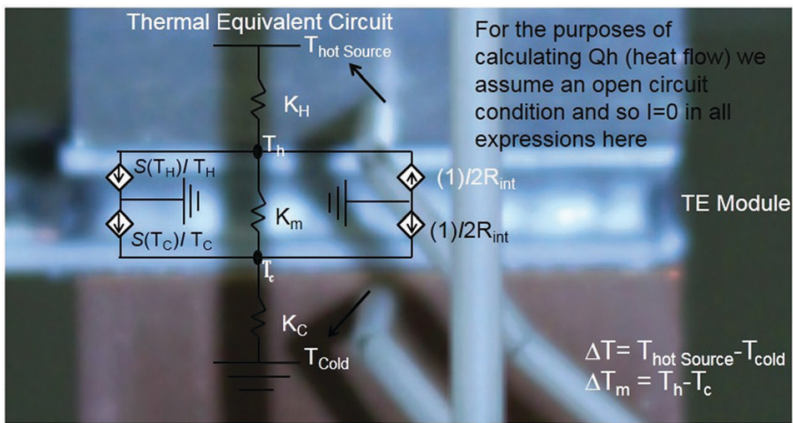

Fig. 9 Illustration of an equivalent thermal circuit superimposed on the image of a thermoelectric module in a 1-D thermal efficiency test stand. In the figure we highlight the extrinsic thermal resistance that effect the temperatures at the hot and cold side of the TE materials. We also highlight thermal and electrical contributions to heat flow which influence the measured thermal to electrical conversion efficiencies. These include Peltier heat pumping effects and Joule heating.

of the 1-D model, it was assumed that the thermal resistance of the aerogel insulation was infinitely large such that all heat flowing through the module did so through the TE elements. A diagram of the thermal equivalent circuit on which this simple 1-D model is based is shown in Fig. 9. From the calculated heat flow we can estimate the temperature drops at each of the thermal resistors to obtain the $\Delta T_{\mathrm{M}}$. From these calculations we can compute $V_{\mathrm{OC}}$ from the relation ${ }^{30}$

$$
V_{\mathrm{OC}}=n \int_{T_{\mathrm{C}}}^{T_{\mathrm{H}}} S(T)_{\mathrm{p}} \mathrm{d} T-n \int_{T_{\mathrm{C}}}^{T_{\mathrm{H}}} S(T)_{\mathrm{n}} \mathrm{d} T
$$

where $T_{\mathrm{H}}$ and $T_{\mathrm{C}}$ are the temperatures at the hot and cold side of the materials as derived from the 1-D model and not the temperatures measured at the boundaries of the TE module, which are denoted as $T_{\text {Hotsource }}$ and $T_{\text {cold }}$ in Fig. 9. $S(T)_{\mathrm{n}, \mathrm{p}}$ are the temperature dependencies of the Seebeck coefficients for the $\mathrm{n}$ - and p-materials, respectively, and $n$ is the number of $\mathrm{p}$ - and n-type elements connected electrically in series.

The simple 1-D model and the temperature drops it predicts can be used in conjunction with eqn (2) to calculate modelled values for the $V_{\mathrm{OC}}$ of a skutterudite module as well as for a PbTe module over the entire temperature range investigated that are in good agreement with measured values. The PbTe module was also built as a prototype for possible use in the TEG, but due to durability concerns this material was eliminated from consideration. The PbTe module data are presented here only to demonstrate how robust the 1-D model is, beyond this no further performance data will be given and details regarding the PbTe module performance can be found elsewhere. ${ }^{22} \mathrm{We}$ found that this simple 1-D model and the same thermal interface contact resistance value could reconcile the discrepancies in $V_{\text {OC }}$ found in both the skutterudite and the PbTe modules; despite large differences in the magnitude and temperature dependencies of their respective $S$ and $\kappa$ values. Fig. 10 shows the modelled and measured $V_{\mathrm{OC}}$ as a function of $\Delta T$ across the module for both the skutterudite and PbTe modules. As can be seen, the 1-D model and the single value for thermal interface contact resistance account well for the behaviour over all temperatures investigated, including higher cold side temperatures. It is based on this excellent level of agreement that we can estimate, with confidence, the value of the temperature difference across the TE element $\left(\Delta T_{\mathrm{M}}\right)$.

The large reduction in the $V_{\mathrm{OC}}$ imposed by thermal resistances extrinsic to the module results in a dramatic reduction in the electrical power output. The electrical power as a function of the $V_{\mathrm{OC}}, R_{\mathrm{int}}$, and the external load resistance $\left(R_{\text {load }}\right)$ is expressed as ${ }^{30}$

$$
P_{\text {out }}=I^{2} R_{\text {load }}=V_{\mathrm{OC}^{2}}^{2}\left[\frac{R_{\text {load }}}{\left(R_{\text {load }}+R_{\text {int }}\right)^{2}}\right] .
$$

It can be inferred from eqn (3) that the maximum power output is obtained when $R_{\text {load }}=R_{\text {int }}$, but more importantly the output power is strongly dependent on $V_{\text {OC }}$. From eqn (3) it can be seen that reductions in the $V_{\text {OC }}$ due to thermal interface contact resistance quickly degrade the performance of the module. Fig. 11 shows the power output of the module as a function of the measured temperature difference across the module $(\Delta T)$ and the modelled temperature difference across the TE element $\left(\Delta T_{\mathrm{M}}\right)$.
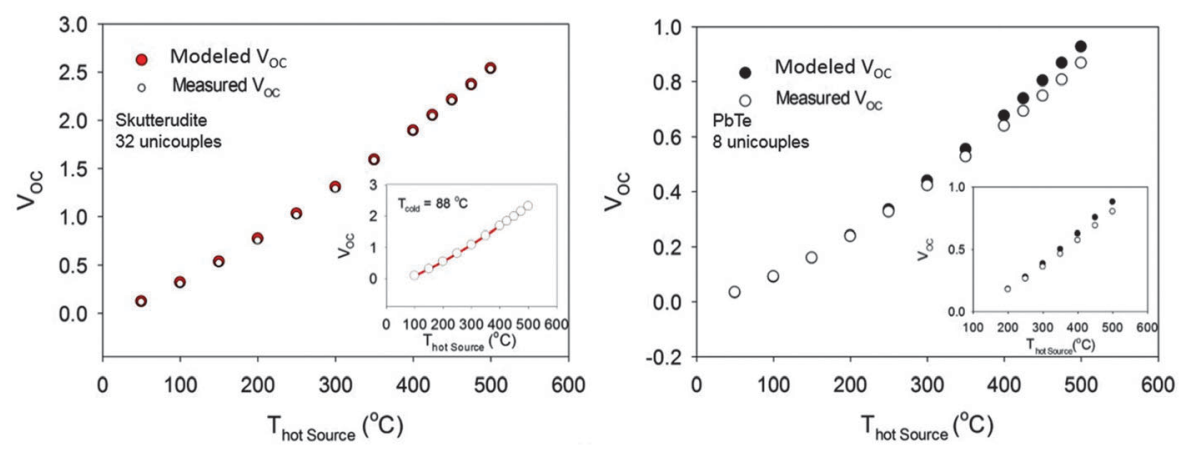

Fig. 10 Modelled and measured $V_{\mathrm{OC}}$ as a function of the hot side temperature of the module. We used a lumped thermal interface contact resistance value which accounts for the resistances between the module and the hot side and cold side of the test stand as well as any thermal interface resistances between the TE legs and the metal interconnects. The value taken as the thermal interface contact resistance is assumed to be symmetric at both module boundaries. The model, and the interface resistance derived from it, accounts well for both the skutterudite and PbTe module despite the fact that the temperature dependence and magnitude of their $\kappa$ and $S$ differ substantially. Reproduced from ref. 22. 


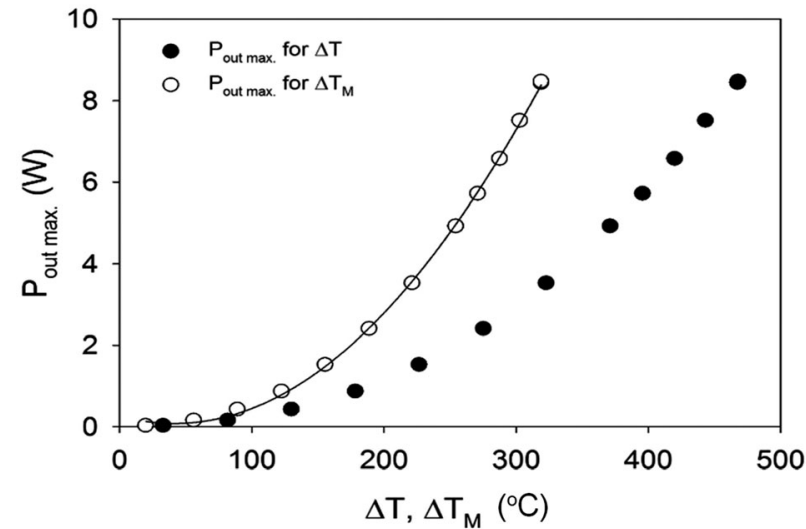

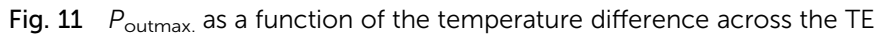
module, $\Delta T$ (filled circles). The open circles are the maximum power output as function of the temperature difference across the materials $\Delta T_{M}$. The values of $\Delta T_{M}$ were based on the $V_{\text {OC }}$ values computed from the 1-D model. Reproduced from ref. 22.

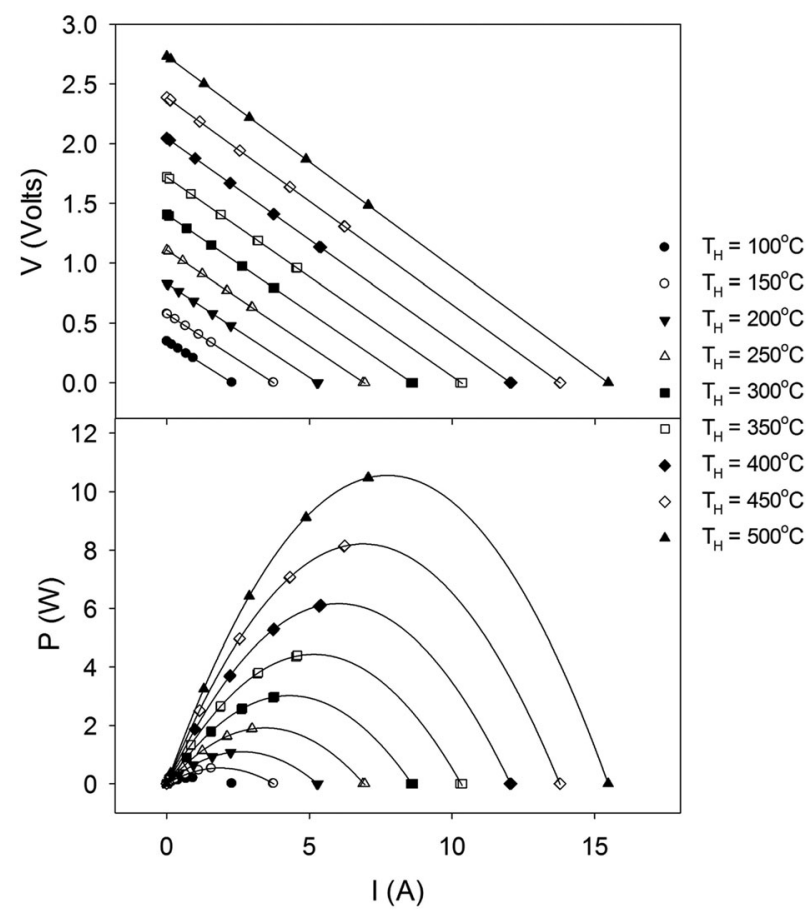

Fig. 12 The top panel shows the voltage of the module as a function of current flow through it. The current is controlled by an adjustable external load resistance. The slope of the $V-I$ curve gives an approximation of the module resistance. The bottom panel shows the module's electrical power output as function of the current drawn by the load. The solid lines in the both panels are fits to the data.

The maximum power output of the TEM was found to be $8.5 \mathrm{~W}$ with a temperature difference of $460{ }^{\circ} \mathrm{C}$ across the module $\left(500{ }^{\circ} \mathrm{C}\right.$ hot side and $40{ }^{\circ} \mathrm{C}$ cold side). However, as can be seen in Fig. 11, $\Delta T_{\mathrm{M}}$ is much smaller, due to the imposition of the thermal contact resistance, and any reduction in this thermal resistance will translate into higher power output for the same temperature difference across the module. In the absence of any thermal resistance between the module and the test stand, we can

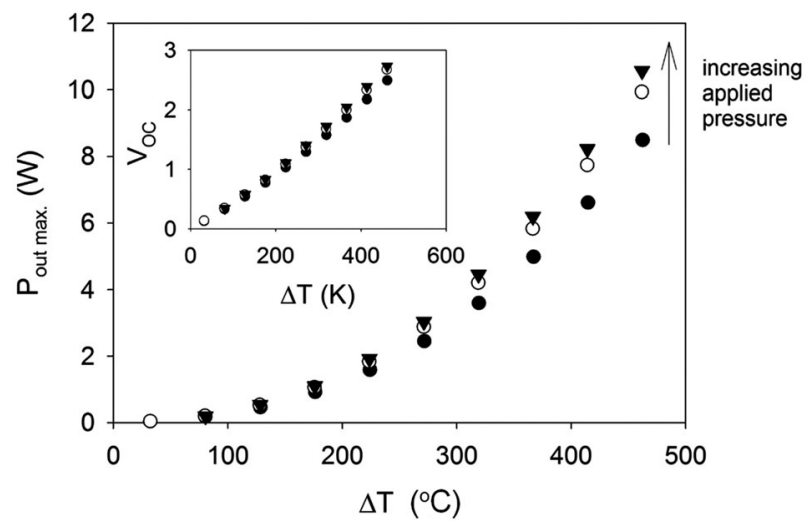

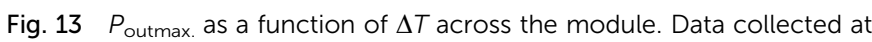
$0.5 \mathrm{MPa}(\bullet),(O)$ the first set of measurements with data taken on heating up to a hot side temperature of $500{ }^{\circ} \mathrm{C}$ at $0.9 \mathrm{MPa}$. $(\boldsymbol{\nabla})$ is the second set of measurements with data being taken on heating up to a hot side temperature of $500{ }^{\circ} \mathrm{C}$. The slightly higher power output of the second higher pressure measurement can be traced to reductions in the module's resistance.

extrapolate that the maximum power output of the module would be $16 \mathrm{~W}$ for a $\Delta T_{\mathrm{M}}=460{ }^{\circ} \mathrm{C}$.

When the pressure was increased the module $V_{\mathrm{OC}}$ increased from $2.48 \mathrm{~V}$ for a $0.5 \mathrm{MPa}$ to $2.66 \mathrm{~V}$, for $0.9 \mathrm{MPa}$ at a module hot side temperature of $500{ }^{\circ} \mathrm{C}$ and a cold side temperature of $40{ }^{\circ} \mathrm{C}$. This corresponds to cutting the thermal interface resistance to $4.0 \times 10^{-4} \mathrm{~m}^{2} \mathrm{~W} \mathrm{~K}^{-1}$. Again this contact resistance value was extracted from a 1-D model, but it was able to reconcile the $V_{\mathrm{OC}}$ values over a broad range of operating temperatures. The increased $V_{\mathrm{OC}}$ results in an increased maximum power output of $10.0 \mathrm{~W}$ at $\Delta T=460{ }^{\circ} \mathrm{C}$. A successive measurement was run upon cool down, and it was found that the $V_{\mathrm{OC}}$ increased further to $2.73 \mathrm{~V}$ at the highest $\Delta T$ value of $460{ }^{\circ} \mathrm{C}$ and a maximum power output of $10.5 \mathrm{~W}$ was achieved. Fig. 12 shows the $V v s . I$ and the $P_{\text {out }} v s . I$ curves for the second measurement performed at $0.9 \mathrm{MPa}$ applied pressure. Fig. 13 shows the maximum power output and $V_{\mathrm{OC}}$ (inset) as a function of the $\Delta T$ for the $0.5 \mathrm{MPa}$ measurement and for the two successive measurements made at $0.9 \mathrm{MPa}$. Measurements made at higher loading pressures of 1.1 MPa and 1.2 MPa failed to improve the module's performance further, and in fact measurements made at $1.2 \mathrm{MPa}$ result in a p-type element cracking and ultimate failure of the module. It should be noted that the pressure on an individual element can be much larger than the average pressure applied to the module.

As noted above, alternate thermal interface materials were also investigated. It was found that in the absence of thermal interface materials at the cold side junction of the module and the test stand and with the application of 0.9 MPa pressure the power output at $\Delta T=460{ }^{\circ} \mathrm{C}$ was reduced to $8.4 \mathrm{~W}$. However when grafoil was used as the cold side interface material and $250 \mu \mathrm{m}$ thick aluminum foil was used at the hot side junction with $0.5 \mathrm{MPa}$ pressure the $V_{\mathrm{OC}}$ increased to $2.81 \mathrm{~V}$ at $\Delta T=460{ }^{\circ} \mathrm{C}$ as compared to $2.48 \mathrm{~V}$ when grafoil was used at both junctions. The power output was increased from $8.5 \mathrm{~W}$ to $10.8 \mathrm{~W}$ at 

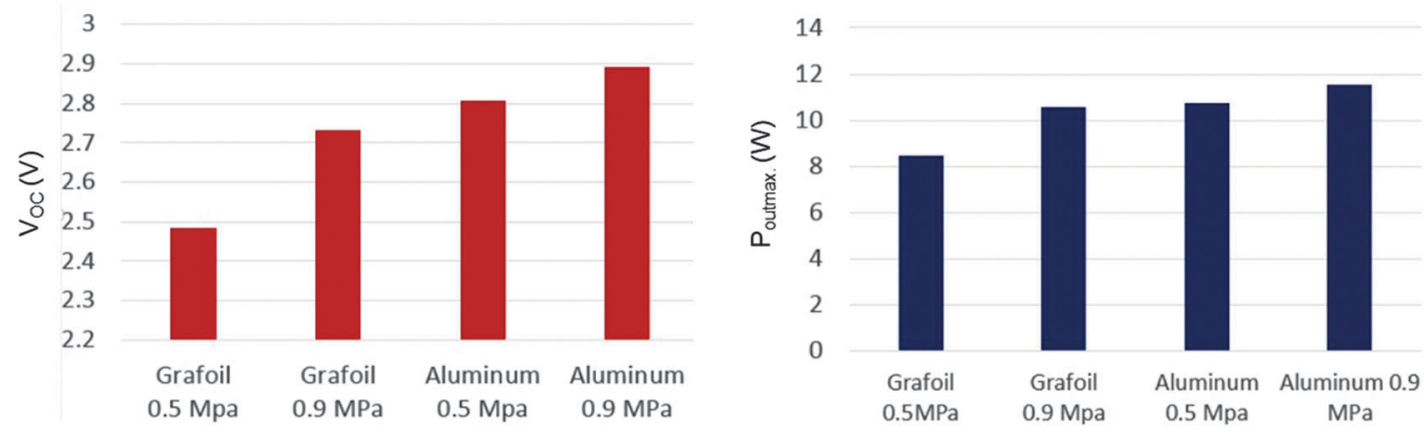

Fig. $14 V_{\mathrm{OC}}$ and $P_{\text {outmax. }}$ of the TEM with different thermal interface materials and loading pressures. All data presented are for a hot side temperature of $500{ }^{\circ} \mathrm{C}$ and a cold side temperature of $40{ }^{\circ} \mathrm{C}$.

$\Delta T=460{ }^{\circ} \mathrm{C}$ and $0.5 \mathrm{MPa}$ as a result of the use of aluminum. When the pressure was increased to $0.9 \mathrm{MPa}$ while still using the aluminum foil TIM the $V_{\mathrm{OC}}$ increased to $2.89 \mathrm{~V}$, and the power output was $11.6 \mathrm{~W}$ at $\Delta T=460{ }^{\circ} \mathrm{C}$. The thermal interface contact resistance for the case of using aluminium foil interface material at the hot side junction is estimated to be $2.0 \times$ $10^{-4} \mathrm{~m}^{2} \mathrm{~K} \mathrm{~W}^{-1}$ at $0.9 \mathrm{MPa}$. The results of the effects of loading pressures and thermal interface material are summarized in Fig. 14. For reference a $V_{\mathrm{OC}}$ value of $3.4 \mathrm{~V}$ would be expected if $T_{\mathrm{C}}=40{ }^{\circ} \mathrm{C}$ and $T_{\mathrm{H}}=500{ }^{\circ} \mathrm{C}$, that is, in the absence of any extrinsic thermal resistance, aside from the ceramic plates between the TE elements and the test stand.

To summarize, we have demonstrated that the maximum power output of a skutterudite module is reduced by over $30 \%$ when the thermal interface contact resistance is increased by a factor of 3. The interface contact resistance estimated for the measurements made at higher loading pressure and using aluminium as the hot side interface material is still unacceptably high. Marlow Industries is currently pursuing development efforts to modify the module architecture to reduce these temperature drops between the heat sources and sinks and the TE materials.

\section{Conversion efficiency}

As noted in eqn (1), the ideal $\eta$ of a TE couple is a function of the temperature difference and the ZT of the materials.
As demonstrated above, there are many factors extrinsic to the module that can influence the power output as well as the heat flow through the module. The thermal to electrical power conversion efficiency for a TE couple can be expressed as $\eta=$ $P_{\text {out }} / Q_{\mathrm{H}}$, where $P_{\text {out }}$ is the electrical power output for a particular $I$ and $R_{\text {load }}$ and $Q_{\mathrm{H}}$ is the heat flow into the hot side of the TE material. Heat flow through the module in the absence of current flow is simply the value calculated from the summed thermal resistance values described above and the temperature difference between source and sink such that, from Fourier's law

$$
Q=\left(T_{\text {hotSource }}-T_{\text {cold }}\right) /\left(K_{\mathrm{H}}+K_{\text {cerH }}+K_{\mathrm{M}}+K_{\text {cerC }}+K_{\mathrm{C}}\right)
$$

where $K_{\mathrm{H}}$ and $K_{\mathrm{C}}$ are the respective thermal interface contact resistances of the hot and cold side of the module, $K_{\text {cerH }}$ and $K_{\text {cerc }}$ are the thermal resistances of the respective hot and cold side ceramic plates, and $K_{\mathrm{M}}$ is the thermal resistance of the TE materials. When current begins to flow and power is generated, two additional terms enter the expression for heat flow, and it is necessary to differentiate between hot side heat flow and cold side heat flow such that ${ }^{30}$

$$
Q_{\mathrm{H}}=\left(T_{\mathrm{H}}-T_{\mathrm{C}}\right) / K_{\mathrm{M}}-\left(S \cdot I \cdot T_{\mathrm{H}}\right)+\left(I^{2} R_{\mathrm{int}}\right) / 2
$$

and

$$
Q_{\mathrm{C}}=\left(T_{\mathrm{H}}-T_{\mathrm{C}}\right) / K_{\mathrm{M}}+\left(S \cdot I \cdot T_{\mathrm{C}}\right)+\left(I^{2} R_{\mathrm{int}}\right) / 2 .
$$
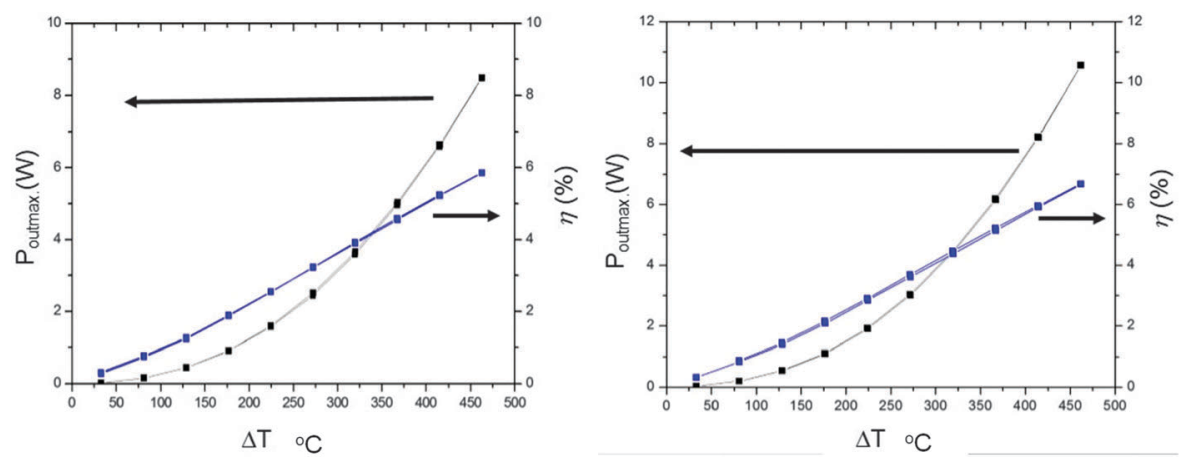

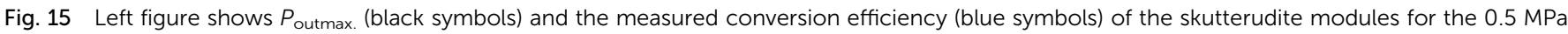
loading pressure. The figure on the right shows the same data for the same module but with a loading pressure of $0.9 \mathrm{MPa}$. The data presented represents the second measurement up to high temperatures with the higher power output. 
These expression are shown graphically in the thermal equivalent circuit in Fig. 9.

Fig. 15 summarizes the conversion efficiencies and power outputs as a function of $\Delta T$ for the $0.5 \mathrm{MPa}$ and the second $0.9 \mathrm{MPa}$ measurements with grafoil thermal interface materials. As can be seen, the lower pressure measurement has a conversion efficiency of $\sim 6 \%$ with a power output of $8.5 \mathrm{~W}$. When the pressure is increased to $0.9 \mathrm{MPa}$, the power output is increased to $10.5 \mathrm{~W}$, and the conversion efficiency increases to $\sim 7 \%$. Though not explicitly measured, we can extrapolate that the conversion efficiency of the module would reach $7.5 \%$ when aluminium foil is used as the interface material and the clamping load on the module is $0.9 \mathrm{MPa}\left(P_{\text {outmax. }}=11.5 \mathrm{~W}\right)$.

These conversion efficiencies are likely underestimated for two reasons. Firstly, the 1-D thermal flux meter which is used to measure the amount of heat entering the module radiates heat from its surface, particularly at temperatures above $300{ }^{\circ} \mathrm{C}$. These losses are not accounted for in the measurement; therefore, the amount of heat entering the module is overestimated and the calculated conversion efficiency is underestimated. Further, similar radiative heat loss mechanisms are operant for the TE materials and the ceramic plates which are also not accounted for in these measurements. Though it is worth pointing out that these losses are part of the reality of TE module operation at high temperature. Secondly, due to the limitations of the variable electrical load tester, the maximum power output is an extrapolated value based on the measured values of the $V_{\mathrm{OC}}$ and $R_{\text {int }}$. The measured module resistance is set equal to the load resistance, and with the measured open circuit voltage the maximum power output is calculated using eqn (3). The $\eta$ reported here is the quotient of the extrapolated $P_{\text {outmax. }}$ value and the measured heat flux delivered to the module. However, in most cases the maximum power output and maximum conversion efficiency for a particular temperature difference occur at different current levels. This is due to the fact that the Peltier and Joule terms in eqn (5) and (6) become non-trivial contributors to $Q_{\mathrm{H}}$, and in general the peak conversion efficiency occurs at a lower current level than the peak power output. Since the load resistance at the peak conversion efficiency was not explicitly measured and was instead estimated from the maximum power output operating point, the efficiency is consequently underestimated.

Of the two effects the radiative losses from the test stand dominate and may lower the measured efficiency value by a full percentage point. The fact that the conversion efficiency was not measured at the correct load resistance may further lower the reported value by $0.1 \%$ to $0.2 \%$. For comparison a recently published study made very carefully controlled measurements of maximum power output and conversion efficiency on a skutterudite unicouple. ${ }^{12}$ In this case the heat source was a Pt resistance heater that was characterized for thermal emissivity and thermal power output prior to couple measurement so that the radiative loss could be taken into account. Thermal emissivity was modelled for the TE materials as well. ${ }^{12}$ The $S, \rho$ and $\kappa$ of the TE elements used in ref. 12 are remarkably similar to those used in the construction of the module presented here, so making a direct comparison of efficiency values is worthwhile.
The maximum power output reported in ref. 12 was $0.45 \mathrm{~W}$ at $6 \mathrm{~A}$ when the TE elements were heated to $560{ }^{\circ} \mathrm{C}$ on the hot side and cooled to $\sim 70{ }^{\circ} \mathrm{C}$ on the cold side. The maximum conversion efficiency was found to be $9.1 \%$ for the same temperature difference at $4.75 \mathrm{~A}$. For comparison, if this couple were expanded into a 32 couple module like that presented here, the power output would be $\sim 14.4 \mathrm{~W}$ or about $20 \%$ higher than the best performance recorded for our module. However we must bear in mind that the temperatures reported for the unicouple were recorded at the hot and cold junctions of the TE materials, while we report the temperatures at the exterior of the module. The higher temperature differences across the material in the unicouple measurements in ref. 12 account for the power output differences. The $\Delta T_{\mathrm{M}}$ from ref. 12 is $\sim 490{ }^{\circ} \mathrm{C}$, and for our modules we estimate the TE element temperature difference to be $400{ }^{\circ} \mathrm{C}$, based on $V_{\text {OC }}$ values, for the most favourable test conditions.

By comparing measured values of conversion efficiency for this unicouple and our module, we find about a 2.2 percentage point discrepancy under similar operating conditions for materials with comparable $\mathrm{ZT}$ values. This can be ascribed to the fact that interface contact resistance in the module level measurements decreased the temperature difference seen across the TE elements, lowering the power output much more significantly than the thermal resistance impedes heat flow through the module. Secondly, both the unicouple and the module had higher than expected resistances, presumably due to electrical contact resistance. These parasitic resistances reduce the power output in a linear fashion, underscoring the importance of minimizing their impact. Finally, the fact that thermal radiative losses were meticulously accounted for in ref. 12 does also enter into the efficiency discrepancy, but it is a much smaller factor than the thermal and electrical contact resistances. Based on 1-D models, we predicted that for our module operating at $500{ }^{\circ} \mathrm{C}$ and $40{ }^{\circ} \mathrm{C}$ at the hot and cold junction of the TE elements and in the absence of any electrical contact resistance, a conversion efficiency close to $9 \%$ would be possible. The measured thermal to electrical energy conversion efficiency reported here is competitive with the values reported for unicouples and is among the best ever reported for fully functioning multi-couple high temperature capable TE modules. For example D'Angelo et al. reported a $\eta=6.6 \%$ for a 47 couple module composed of segmented $\mathrm{PbTe} / \mathrm{Bi}_{2} \mathrm{Te}_{3}$ elements operating at $400{ }^{\circ} \mathrm{C}$ on the hot side and $40{ }^{\circ} \mathrm{C}$ on the cold side. ${ }^{9}$ Though comparable conversion efficiency was obtained for this module despite the lower $\Delta T$, segmentation of the TE legs is deemed undesirable for automotive applications due to added complexity and durability concerns. Zhaoa et al. have reported an $\eta=6.4 \%$ for a skutterudite based module operating between $540{ }^{\circ} \mathrm{C}$ and $47{ }^{\circ} \mathrm{C}$ on the hot and cold side respectively. The method used to evaluate the heat flow into the module was not explicitly stated in their report, and so establishing to what degree this value may be underestimated is difficult. ${ }^{18}$ Recently, there has been a report of a skutterudite module that claims a conversion efficiency of $8 \%$ when operating at $600{ }^{\circ} \mathrm{C}$ and $30{ }^{\circ} \mathrm{C} .{ }^{31}$ The module in that study did not have a ceramic plate 
to isolate the current and instead relied on electrically insulating thermal interface materials for testing. ${ }^{31}$

\section{Summary and conclusions}

We have presented the power output and conversion efficiency for a 32 couple skutterudite module. Although the data presented are for only one of the thirty such modules made for the GM TEG prototype, we conclude that its performance is representative of the majority of the modules fabricated. This is due to the fact that 26 of the 30 modules have very similar values for AC resistance, and $\mathrm{AC}$ resistance is a sensitive measure of module quality. We investigated the effects of clamping force and thermal interface materials on the modules overall performance. We find that higher clamping forces reduce the thermal interface contact resistance between the module and the test stand and that using thin metal foils such as Al is highly beneficial. The maximum power output of the module with a $\Delta T=460{ }^{\circ} \mathrm{C}$ was $8.0 \mathrm{~W}$ when no interface material was used between the heater and the module and with $0.5 \mathrm{MPa}$ of pressure. The power output was increased to $8.5 \mathrm{~W}$ for the same operating conditions when grafoil was used and a pressure of 0.5 MPa was applied. The power output increased further to $10.5 \mathrm{~W}$ when the pressure was increased to 0.9 MPa. Finally with $\mathrm{Al}$ foil as an interface material on the hot side the maximum power output of the module with a $\Delta T=460{ }^{\circ} \mathrm{C}$ was 10.8 and $11.5 \mathrm{~W}$ for loading pressures of 0.5 and $0.9 \mathrm{MPa}$, respectively. The increased power output is attributable to the decrease in the thermal interface contact resistance between the module and the test stand which led to smaller temperature drops between the heat source and sink and the respective TE element temperatures and concomitantly larger $V_{\mathrm{OC}}$ values.

A 1-D thermal heat flux bar was used to estimate the heat flow through the module to estimate the conversion efficiency. These measurements were made only for the case when grafoil was used as the interface material. We estimate that for $0.5 \mathrm{MPa}$ loading pressures the $8.5 \mathrm{~W}$ of power output equates to a $6 \%$ thermal to electrical thermal conversion efficiency, while the higher pressure measurement obtains $10.5 \mathrm{~W}$ of power and a $7 \%$ conversion efficiency. While not measured we can extrapolate to a conversion efficiency of $7.5 \%$ for the higher pressure measurement that used $\mathrm{Al}$ foil as the interface material to obtain $11.5 \mathrm{~W}$ of electric power. The power outputs reported here and the conversion efficiencies are comparable to reported values for measurements performed on unicouples, and they are among the highest values reported for a fully functioning high temperature capable module. These conversion efficiency values are underestimated since radiative loss from the 1-D bar and the TE module materials was not taken into count, and therefore the heat flow $\left(Q_{\mathrm{H}}\right)$ is overestimated.

\section{Acknowledgements}

JRS, JYC, and ZY would like to thank J. F. Herbst and M. W. Verbrugge for their continued support and encouragement. This work is supported by GM, Marlow Industries (a subsidiary of II-VI Inc.), and by DOE under corporate agreement DE-FC26-04NT42278 and DE-EE0005432. TT and J. Sakamoto would like to acknowledge support from the Revolutionary Materials for Solid State Energy Conversion, an Energy Frontier Research Center funded by the US Department of Energy, Office of Science, Office of Basic Energy Science under Award Number DE-SC001054. This research was partially performed at the Oak Ridge National Laboratory (ORNL) and sponsored GM Global R\&D under the Materials Science and Technology Division, Work-for-Others (WFO) Program, IAM: 14687701, and DOE agreement: NFE-12-03934, with the U.S. Department of Energy.

\section{References}

1 K. Biswas, J. He, I. D. Blum, C.-I. Wu, T. P. Hogan, D. N. Seidman, V. P. Dravid and M. G. Kanatzidis, Nature, 2012, 489, 414-418.

2 X. Shi, J. Yang, J. R. Salvador, M. F. Chi, J. Y. Cho, H. Wang, S. Q. Bai, J. Yang, W. Q. Zhang and L. D. Chen, J. Am. Chem. Soc., 2011, 133, 7837-7846.

3 S. N. Girard, J. Q. He, X. Y. Zhou, D. Shoemaker, C. M. Jaworski, C. Uher, V. P. Dravid, J. P. Heremans and M. G. Kanatzisis, J. Am. Chem. Soc., 2011, 133, 16588-16597.

4 P. F. P. Poudeu, J. D'Angelo, A. D. Downey, J. L. Short, T. P. Hogan and M. G. Kanatzidis, Angew. Chem., Int. Ed., 2006, 45, 3835-3839.

5 J. Yang and T. Caillat, Mater. Res. Bull., 2006, 31, 224-229.

6 J. G. Snyder and E. S. Tober, Nat. Mater., 2008, 7, 105-114, and references therein.

7 M. El-Genk, H. Saber and T. Caillat, AIP Conf. Proc., 2004, 699, 541-552.

8 M. El-Genk, H. Saber, T. Caillat and J. Sakamoto, Energy Convers. Manage., 2006, 47, 174-200.

9 J. D’Angelo, E. Case, N. Matchanov, C. Wu, T. Hogan, J. Barnard, C. Cauchy, T. Hendricks and M. Kanatzidis, J. Electron. Mater., 2011, 40, 10-15.

10 M. Kambe, T. Jinushi and Z. Ishijima, J. Electron. Mater., 2010, 39, 9.

11 K. Salzgeber, P. Prenninger, A. Grytsiv, P. Rogl and E. Bauer, J. Electron. Mater., 2009, 39, 2074-2078.

12 A. Muto, J. Yang, B. Poudel, Z. F. Rern and G. Chen, Adv. Energy Mater., 2012, 3, 245-251.

13 H. Saber, M. El-Genk and T. Caillat, AIP Conf. Proc., 2005, 746, 584-592.

14 Z. Gu, Y. Han, F. Pan, X. Wang, D. Weng and S. Zhou, Mater. Sci. Forum, 2009, 610-613, 389-393.

15 D. Zhao, X. Li, L. He, W. Jiang and L. Chen, J. Alloys Compd., 2009, 477, 425-431.

16 J. Fan, L. Chen, S. Bai and X. Shi, Mater. Lett., 2004, 58, 3876-3878. 17 X. Li, L. Chen, J. Fan, S. Bai, ICT Proc., 2005, pp. 540-542.

18 D. Zhaoa, C. Tiana, S. Tanga, Y. Liua, L. Jianga and L. Chen, Mater. Sci. Semicond. Process., 2010, 13, 221-224.

19 T. Nemoto, T. Iida, J. Sato, T. Sakamoto, T. Nakajima and Y. Takahashi, J. Electron. Mater., 2012, 41, 1312-1316.

20 J. Q. Guo, H. Y. Geng, T. Ochi, S. Suzuki, M. Kikuchi, Y. Yamaguchi and S. Ito, J. Electron. Mater., 2012, 41, 1036-1042. 
21 C.-H. Lim, S.-M. Choi, W.-S. Seo and H.-H. Park, J. Electron. Mater., 2012, 41, 1247-1255.

22 J. R. Salvador, J. Y. Cho, Z. Ye, J. E. Mocygemba, A. J. Thompson, J. W. Sharp, J. D. König, R. Maloney, T. Thompson, J. Sakamoto, H. Wang, A. A. Wereszczak and G. P. Meisner, J. Electron. Mater., 2013, 42, 1389-1399.

23 T. Caillat, J. Fleurial, G. Snyder, A. Zoltan, D. Zoltan, A. Borshchevsky, ICT Proc., 1999, pp. 473-476.

24 T. Caillat, J. Fleurial, G. Snyder, A. Borshchevsky, ICT Proc., 2001, pp. 282-285.

25 K. Yazawa and A. Shakouri, Environ. Sci. Technol., 2011, 45, 7548-7553.
26 J. R. Salvador, R. McCarty, H. Wang, A. Yamamoto, J. König, CL-13-365-CMS.

27 J. R. Salvador, J. Yang, A. A. Wereszczak, H. Wang and J. Y. Cho, Sci. Adv. Mater., 2011, 3, 1-10.

28 J. Sakamoto, R. Maloney and T. Thompson, Porous gels and methods and structures related thereto, Filed non-Provisional Patent, WO 2013/009984 A2 MSU, 2013.

29 H. Li, X. F. Tang, T. X. Liu, C. Song and Q. J. Zhang, Acta Phys. Sin., 2005, 54, 5481.

30 H. J. Goldsmid, Electronic Refrigeration, Pion Limited, London, 1986.

31 J. Q. Guo, H. Y. Geng, T. Ochi, S. Suzuki, M. Kikuchi, Y. Yamaguchi, S. Ito, ICT 2013, Kobe, Japan. 